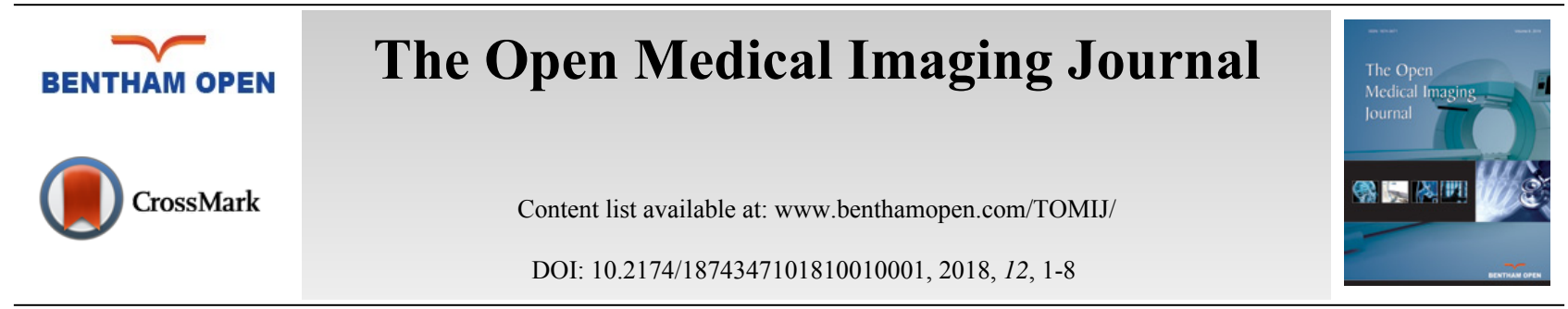

RESEARCH ARTICLE

\title{
Modifications of Midfacial Soft-Tissue Thickness Among Different Skeletal Classes in Italian Children
}

\author{
Daniele Gibelli ${ }^{1, *}$, Matteo Zago ${ }^{1,2}$, Annalisa Cappella ${ }^{1}$, Claudia Dolci $^{1}$ and Chiarella Sforza ${ }^{1}$

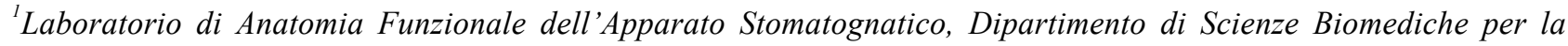 \\ Salute, Università degli Studi di Milano, V. Mangiagalli, 31, Milan, Italy \\ ${ }^{2}$ Department of Electronics, Information and Bioengineering (DEIB), Politecnico di Milano, Milano, Italy
}

Received: April 1, 2018

Revised: September 17, 2018

Accepted: September 24, 2018

\begin{abstract}
:
Background:

The anatomical assessment of the arrangement of facial soft tissues has important applications in different fields from orthodontics to plastic surgery. One of the issues concerns the relationship between facial soft tissue thickness and skeletal class. Literature mainly deals with adult populations, whereas very few studies have been focused on children.
\end{abstract}

\section{Objective:}

This study aims at investigating the relationship between midline facial soft tissue thickness and skeletal classes in Italian pretreatment orthodontic child patients.

\section{Methods:}

Lateral cephalometric X-ray films were obtained from 220 healthy Caucasoid children (91 males and 129 females), aged between 6 and 18 years (Class I: 41 males and 70 females; Class II: 18 males and 25 females; Class III: 32 males and 34 females). All the films were digitized and 14 soft tissue thicknesses were measured on the midface; in addition, the skeletal class was assessed according to the corrected ANB angle (ANBc). Differences in facial soft tissue thickness according to sex and skeletal class were assessed through two-way ANOVA test $(\mathrm{p}<0.01)$.

\section{Results:}

Statistically significant differences according to sex were found for labrale superius, stomion and labrale inferius, with thicker soft tissues in males than in females $(\mathrm{p}<0.01)$. Only measurements at labrale superius and gnathion showed statistically significant differences according to skeletal class, with thicker soft tissues in Class III children and thinner ones in Class II children ( $p<0.01)$.

\section{Conclusion:}

The limited number of investigations, as well as the differences in protocols, renders the comparison of results from different studies difficult, suggesting further investigations to enlighten this complex and debated anatomical issue.

Keywords: Anatomy, Face, Maxillofacial surgery, Soft-tissue thickness, Skeletal class, Cephalometric X-rays.

\section{INTRODUCTION}

One of the most important fields of research in anatomy concerns the face and its role in determining social contacts [1], with special regard to main anatomical structures involved in our external appearance: the dentoskeletal elements and the facial soft tissue thickness [2]. In addition, the assessment of facial anatomical structures has practical

* Address correspondence to this author at the Dipartimento di Scienze Biomediche per la Salute, Università degli Studi di Milano, V. Mangiagalli, 31, Milan, Italy; Tel: +39-02-50315399; E-mail: daniele.gibelli@unimi.it 
applications in orthodontics and plastic surgery for planning the most adequate treatment and predicting possible modifications of the external appearance according to the canons of normality [3, 4]. From this point of view, anatomical research gives an important contribution through different types of investigation, including population studies of facial metrical and qualitative characteristics [5, 6], 3D assessment of facial surface through threedimensional image acquisition systems [7 - 9], and the assessment of relationships between facial soft tissues and the underlying bone and dental surfaces [1, 3, 4, 10 - 18]. Population studies aim at exploring the same facial parameters in different populations to verify possible ethnic variations and establish specific canons.

Despite its importance, the anatomical relationships between dentoskeletal structures and the soft tissues have not been fully investigated. Among others, the relationship between the skeletal class (relative anteroposterior position of maxilla and mandible) and the facial soft tissue thickness has been analysed by a limited number of articles, mainly dealing with adults, whereas even less studies were performed on children [18 - 20]. For instance, a recent paper assessed the relationships between facial measurements and sex and age in children [21], but did not report data about different skeletal classes.

The present study aims at filling this gap and giving a contribution to the actual issue concerning the relationship between facial soft tissue and skeletal class, to improve information concerning the anatomical structure of the face.

\section{MATERIAL AND METHODS}

This retrospective study was performed on 220 lateral cephalometric pre-treatment X-rays obtained from 220 healthy Italian children (91 boys and 129 girls), aged between 6 and 18 years (mean age, SD 10.3 \pm 2.7 years and $10.8 \pm 2.8$ years, respectively for males and females); all patients underwent radiological examinations for orthodontic treatment. Exclusion criteria were possible diseases and pathologies affecting facial soft tissues, facial deformities, history of previous or present facial trauma or orthodontic treatment. All the children were Caucasoid. The experimental project was performed according to local ethical laws and Declaration of Helsinki.

The lateral cephalometric radiographs were digitized with a metrical reference and analysed through Adobe Photoshop CS6 ${ }^{\circledR}$ software.

After setting the Frankfurt Horizontal Plane (FHP), 14 measurements were taken at 14 mid-facial landmarks, according to George ([22], Fig. 1): supraglabella (Sg'), glabella (G'), nasion (N'), nasale (Na'), subnasale (Sn), superior labial sulcus (SLS), labrale superius (LS), stomion (Sto), Labrale Inferius (LI), Inferior Labial Sulcus (ILS), Suprapogonion (S Pog'), pogonion (Pog'), gnathion (Gn'), menton (Me'). On each X-ray, the skeletal class was assessed as well: five landmarks were identified, corresponding to the deepest point of the line between the nasal spine and the prosthion (A - subspinale), the deepest point on the line between infradentale and pogonion (B - supramentale), the lowest point of the chin (Menton, Me), the point at the mandibular angle (gonion, Go), and the central point of the sella turcica (S - sella). Angles ANB (subspinale-nasion-supramentale), SNA (sella-nasion-subspinale) and SN-GoMe (angle between the sella-nasion line and the mandibular plane) were measured [18]. Finally, the corrected ANB angle (ANBc) was calculated according to Miralles et al., as follows [23]:

$$
\mathrm{ANBc}=\mathrm{ANB}+0.5^{*}\left(81.5^{\circ}-\mathrm{SNA}\right)+0.25 *\left(32^{\circ}-\mathrm{SN}-\mathrm{GoMe}\right)
$$

ANBc angles between $0^{\circ}$ and $4^{\circ}$ were classified Class I, under $0^{\circ}$ Class III and over $4^{\circ}$ Class II (Fig. 2).

Each measurement was taken a second time by the same observer and by another operator to test intra- and interobserver variability. Student's t-test was applied to test possible statistically significant differences $(\mathrm{p}<0.01)$.

Two-way ANOVA test was performed to assess possible statistically significant modifications of facial parameters according to skeletal classes and sex, as well as their interaction $(p<0.01)$. In case of statistically significant differences according to skeletal class, post-hoc Tukey HSD tests were performed.

\section{RESULTS}

Among males, 41 belonged to Class I, 18 to Class II and 32 to Class III; among females, 70 were included in Class I, 25 in Class II and 34 in Class III.

No statistically significant intra- and inter- observer differences were found $(\mathrm{p}>0.01)$. 


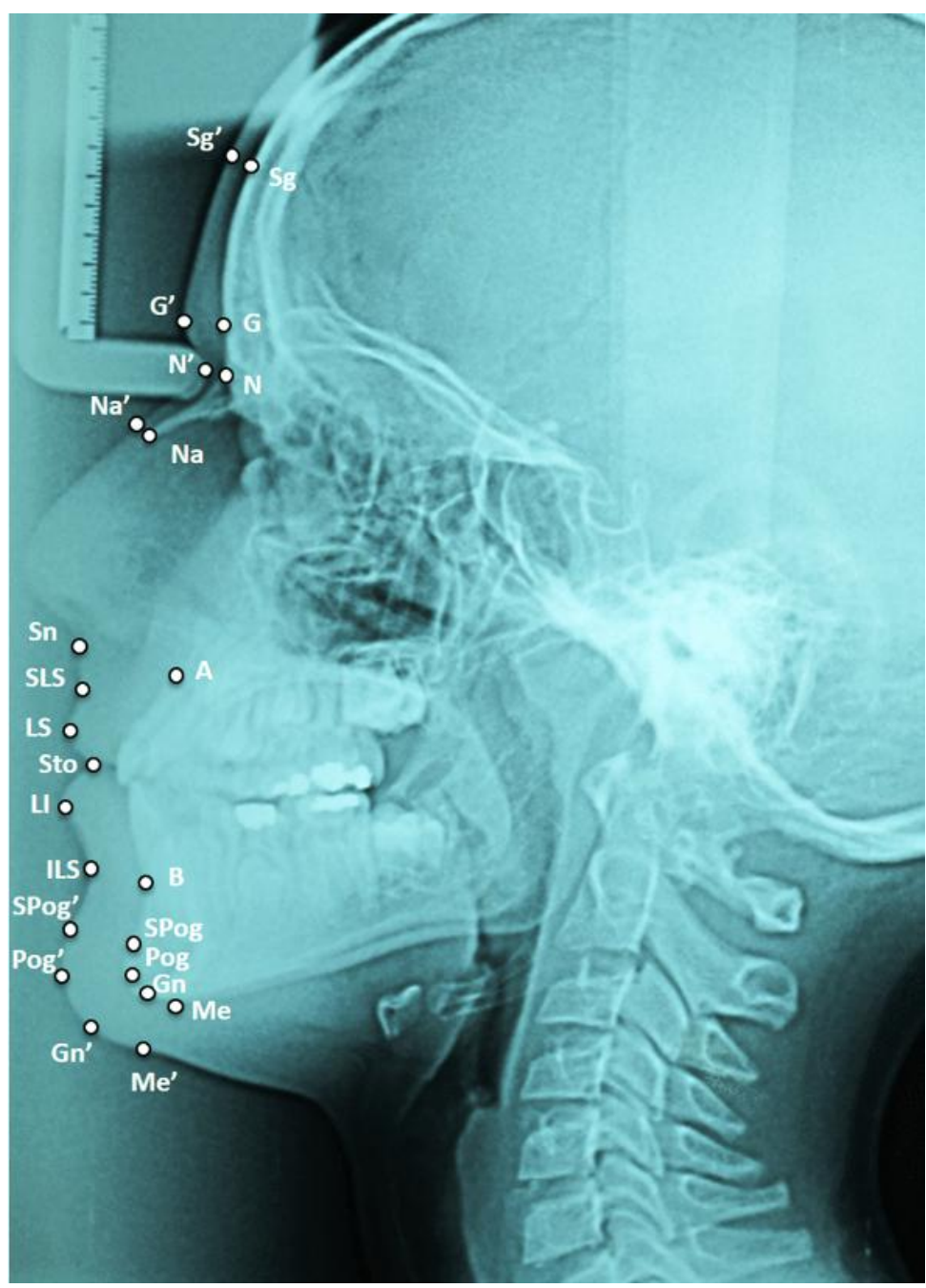

Fig. (1). Cranial landmarks according to George (20): supraglabella (Sg), glabella (G), nasion (N), nasale (Na), Point A (A), Point B (B), suprapogonion (SPog), pogonion (Pog), gnathion (Gn), menton (Me). Facial landmarks: supraglabella (Sg'), glabella (G'), nasion (N'), nasale (Na'), subnasale (Sn), superior labial sulcus (SLS), labrale superius (LS), stomion (Sto), labrale inferius (LI), inferior labial sulcus (ILS), suprapogonion (SPog'), pogonion (Pog'), gnathion (Gn'), menton (Me').
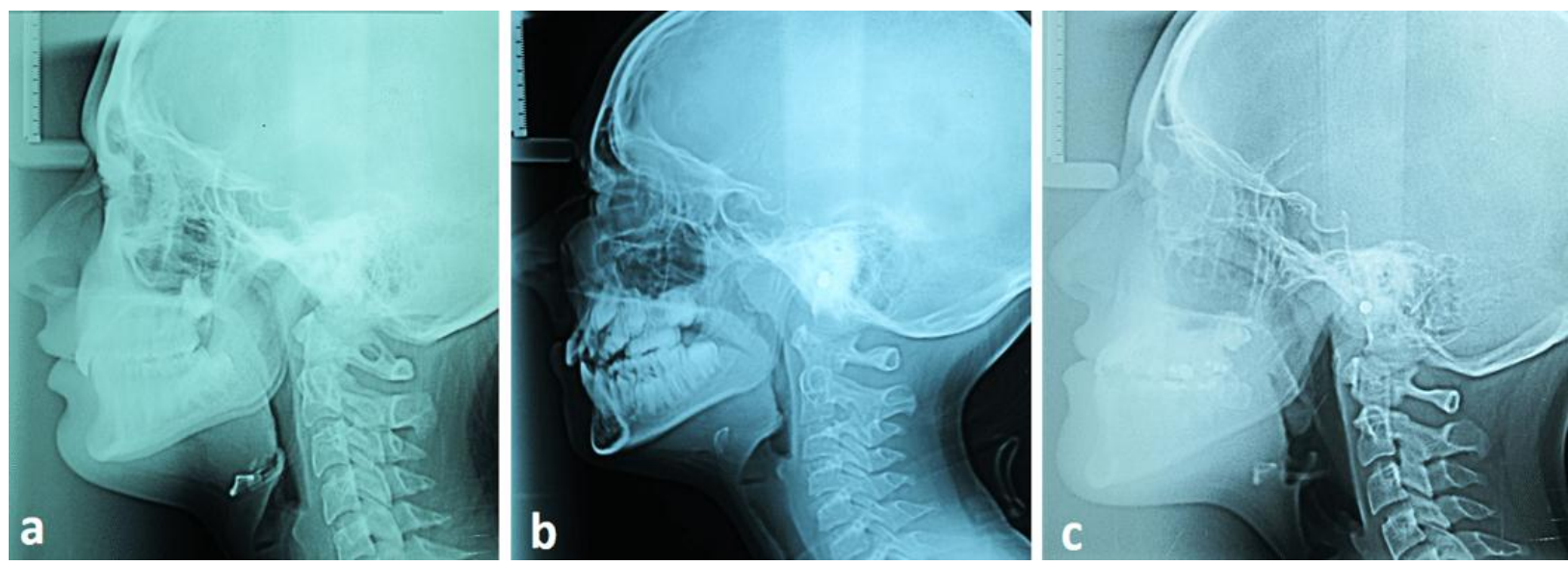

Fig. (2). Example of children with different skeletal classes a) Class I 17-year-old boy; ANBc angle 3.8 $8^{\circ}$ b) Class II 11-year-old boy; ANBc angle $6.5^{\circ}$; c) Class III 16-year-old boy; ANBc angle $-1.8^{\circ}$. 
Overall results are shown in Tables $\mathbf{1}$ and 2, Statistically significant differences according to sex were found for labrale superius, stomion and labrale inferius, with thicker soft tissues in males than in females in all the skeletal classes $(\mathrm{p}<0.01$, Fig. 3).

Soft tissue thicknesses at labrale superius and gnathion showed statistically significant differences according to skeletal class $(\mathrm{p}<0.01)$. For gnathion landmark in both sexes and labrale superius landmark in males, post-hoc tests highlighted statistically significant differences among the three classes: Class III had the thickest soft tissue layer, Class I an intermediate value, and Class II the thinnest layer $(\mathrm{p}<0.01)$.

Table 1. Mean and standard deviation of soft-tissue thicknesses in each mid-facial landmark divided by sex and three skeletal classes; all the measurements are reported in $\mathbf{m m}$.

\begin{tabular}{|c|c|c|c|c|c|c|c|c|c|c|c|c|}
\hline \multirow{3}{*}{ - } & \multicolumn{6}{|c|}{ Males } & \multicolumn{6}{|c|}{ Females } \\
\hline & \multicolumn{2}{|c|}{$\begin{array}{l}\text { I Class } \\
(n=41)\end{array}$} & \multicolumn{2}{|c|}{$\begin{array}{l}\text { II Class } \\
(n=18)\end{array}$} & \multicolumn{2}{|c|}{$\begin{array}{l}\text { III Class } \\
(\mathbf{n}=\mathbf{3 2})\end{array}$} & \multicolumn{2}{|c|}{$\begin{array}{l}\text { I Class } \\
(n=70)\end{array}$} & \multicolumn{2}{|c|}{$\begin{array}{c}\text { II Class } \\
(\mathbf{n}=\mathbf{2 5})\end{array}$} & \multicolumn{2}{|c|}{$\begin{array}{c}\text { III Class } \\
(\mathbf{n}=\mathbf{3 4})\end{array}$} \\
\hline & Mean & SD & Mean & SD & Mean & SD & Mean & SD & Mean & SD & Mean & SD \\
\hline Supra glabella & 4.5 & 0.9 & 3.9 & 0.6 & 4.5 & 0.7 & 4.4 & 0.8 & 4.6 & 0.7 & 4.4 & 0.7 \\
\hline Glabella & 6.1 & 0.8 & 5.8 & 0.9 & 6.2 & 1.0 & 6.0 & 1.0 & 6.0 & 0.9 & 6.0 & 0.9 \\
\hline Nasion & 5.9 & 1.7 & 5.8 & 1.6 & 5.8 & 1.6 & 6.0 & 1.8 & 5.9 & 2.0 & 6.1 & 1.6 \\
\hline Nasale & 2.4 & 0.5 & 2.3 & 0.5 & 2.6 & 0.8 & 2.4 & 0.6 & 2.2 & 0.5 & 2.3 & 0.5 \\
\hline Subnasale & 14.0 & 2.5 & 14.0 & 1.6 & 15.0 & 3.4 & 14.0 & 2.1 & 13.8 & 2.3 & 14.5 & 2.3 \\
\hline Superior labial sulcus & 13.7 & 1.9 & 13.0 & 1.3 & 14.5 & 2.4 & 13.8 & 1.5 & 13.4 & 1.9 & 13.9 & 1.8 \\
\hline Labrale superius & 12.0 & 2.2 & 10.8 & 1.7 & 12.6 & 2.6 & 11.4 & 1.7 & 10.0 & 2.7 & 11.4 & 2.1 \\
\hline Stomion & 5.8 & 2.2 & 4.6 & 1.6 & 5.4 & 1.8 & 4.2 & 2.1 & 4.5 & 3.3 & 5.2 & 2.2 \\
\hline Labrale inferius & 13.4 & 1.7 & 13.0 & 1.6 & 13.5 & 2.1 & 12.8 & 1.7 & 12.4 & 2.3 & 12.6 & 1.6 \\
\hline Inferior labial sulcus & 10.5 & 1.5 & 10.6 & 1.8 & 10.7 & 1.6 & 10.4 & 1.5 & 10.5 & 1.4 & 10.4 & 0.9 \\
\hline Suprapogonion & 11.6 & 2.1 & 11.0 & 1.9 & 11.7 & 2.1 & 11.3 & 1.8 & 10.9 & 1.3 & 11.2 & 1.3 \\
\hline Pogonion & 9.2 & 2.4 & 8.7 & 3.2 & 9.8 & 2.3 & 9.1 & 2.2 & 8.3 & 1.7 & 9.5 & 1.9 \\
\hline Gnathion & 7.1 & 2.3 & 6.0 & 1.4 & 7.4 & 1.8 & 6.8 & 1.9 & 6.4 & 1.3 & 7.4 & 1.9 \\
\hline Menton & 8.6 & 2.1 & 7.3 & 1.8 & 8.5 & 1.6 & 7.9 & 1.6 & 7.6 & 1.5 & 7.6 & 1.5 \\
\hline
\end{tabular}

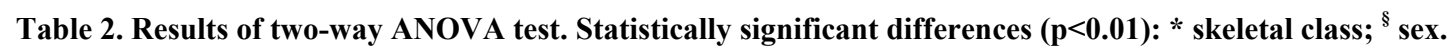

\begin{tabular}{|c|c|c|c|c|c|c|}
\hline \multirow{3}{*}{-} & \multicolumn{6}{|c|}{ Two-way ANOVA test } \\
\hline & \multicolumn{2}{|c|}{ Sex } & \multicolumn{2}{|c|}{ Skeletal class } & \multicolumn{2}{|c|}{$\begin{array}{c}\text { Interaction } \\
\text { sex } \mathrm{x} \text { skeletal class } \\
\end{array}$} \\
\hline & $\mathbf{F}$ & $\mathbf{P}$ & $\mathbf{F}$ & $\mathbf{P}$ & $\mathbf{F}$ & $\mathbf{P}$ \\
\hline Supra glabella & 0 & 1 & 0.85 & 0.4289 & 4.25 & 0.0155 \\
\hline Glabella & 0 & 1 & 0.59 & 0.5552 & 1.18 & 0.3093 \\
\hline Nasion & 0.34 & 0.5604 & 0.17 & 0.8438 & 0 & 1 \\
\hline Nasale & 3.06 & 0.0817 & 1.53 & 0.2189 & 0 & 1 \\
\hline Subnasale & 0.52 & 0.4716 & 2.32 & 0.1007 & 0.17 & 0.8438 \\
\hline Superior labial sulcus & 0.3 & 0.5845 & 3.48 & 0.0326 & 1.36 & 0.2589 \\
\hline Labrale superius * $\S$ & 9.05 & 0.0029 & 8.49 & 0.0003 & 0.11 & 0.8959 \\
\hline Stomion $\S$ & 8.51 & 0.0039 & 1.72 & 0.1815 & 2.23 & 0.11 \\
\hline Labrale inferius § & 7.16 & 0.008 & 0.78 & 0.4597 & 0.16 & 0.8522 \\
\hline Inferior labial sulcus & 0.46 & 0.4984 & 0 & 1 & 0.23 & 0.7947 \\
\hline Suprapogonion & 1.55 & 0.2145 & 1.24 & 0.2915 & 0.15 & 0.8608 \\
\hline Pogonion & 0.78 & 0.3781 & 3.52 & 0.0313 & 0 & 1 \\
\hline Gnathion * & 0.28 & 0.5972 & 5.26 & 0.0059 & 0.43 & 0.6511 \\
\hline Menton & 5.53 & 0.0196 & 2.42 & 0.0914 & 2.07 & 0.1287 \\
\hline
\end{tabular}




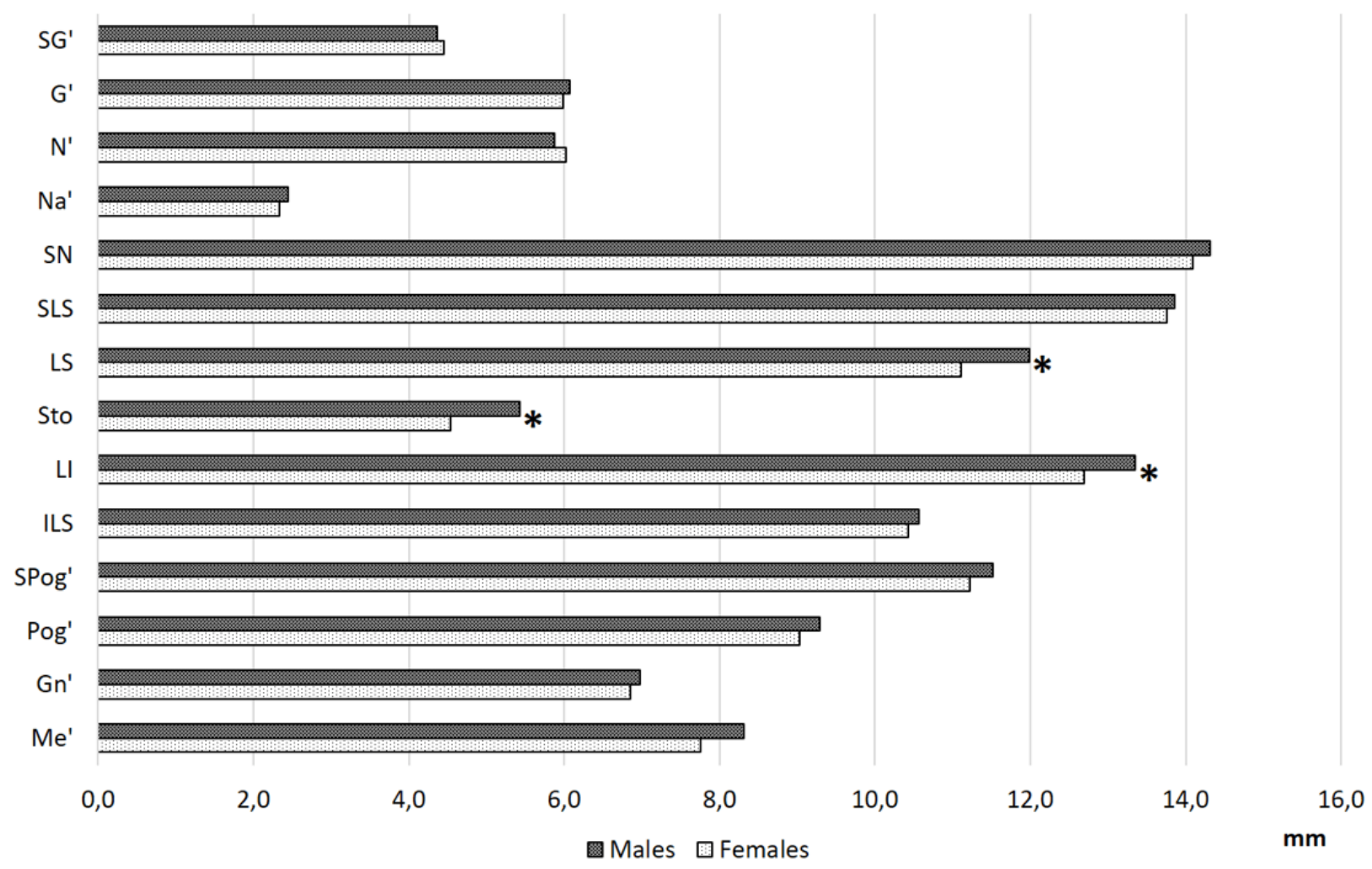

Fig. (3). Overall values of facial soft tissue thickness at each facial landmark in males and females; *: Statistically significant differences according to sex (two-way ANOVA test, $\mathrm{p}<0.01$ ).

In females, soft tissue thickness at labrale superius was significantly larger in Classes I and III than in Class II.

No significant sex x skeletal class interactions were found for all variables.

\section{DISCUSSION}

The assessment of facial soft tissue thickness has many clinical and surgical applications, and is a field of research which may take an important advantage from anatomy. The search for anatomical relationships between soft tissues and underlying bones and teeth is crucial to enlighten the inner rules concerning the construction of facial anatomy and is the key to obtain possible predicting models or canons of facial harmony. One of the still debated issues concerns possible differences of facial soft tissues thickness according to skeletal classes [18].

Literature on adults reports general rules according to which soft tissues are thicker in areas with less skeletal growth: for example, patients with skeletal Class III with an overgrowth of the mandibular region present a thicker layer of soft tissues in the maxillary area, and vice versa [11]. This conclusion confirms the statement by Dumont who verified that skeletal classes influence soft tissue thickness, as the latter one in the chin region decreases with the increase of mandibular protrusion [24]. On the other hand, thicknesses at the upper third of the face do not significantly change as soft tissues are adherent to the bone [8].

However, although general indications concerning the construction of face are provided, results given by studies performed on different population groups show some discordances. Hamid and Abuaffan [1] in a Sudanese population found that Class II showed thinner soft tissues in the upper lip region (subnasale, labrale superius and stomion), whereas in Class III the lower facial region (labrale inferius, labiomental sulcus, pogonion) had the thinnest soft-tissue layers.

Utsuno et al., [11] in a Japanese group found differences in facial soft tissue thickness at labrale inferius in males (higher in Class II), and at subnasale, labrale superius, stomion (higher in Class III), labiomentale and pogonion (higher in Class II) in females.

Kurkcuoglu et al., [13] in a Turkish population confirmed that most of the modifications involve the middle and lower thirds of face, with the highest differences among Classes at nasion, labrale superius, stomion (higher in Classes I 
and III) and subnasale (higher in Classes II and III) in males; at labrale superior, pogonion (higher in Class III) and labrale inferius (higher in Class II) in females. On the other side, in a similar Turkish population Kamak and Celikoglu [15] found a statistically significant increase of soft tissue thickness at labrale superius and stomion in Class III, at labrale inferius in Class II. Gungor et al., [17] in a Central Anatolian group found differences in soft tissue thicknesses at rhinion, labrale superius (higher in Class III) and labrale inferius (higher in Class II) in males, and at nasion and labrale inferius in females (higher in Class II).

Wang et al., [10] in a Chinese population found a statistically significant variation according to skeletal classes only at stomion, being thicker in Class III than in the other two Classes.

The discordances between studies may find different reasons: first, in some cases, results are not comparable, as some authors classify skeletal classes according to different angle thresholds [11]. Secondarily racial variations exist, as highlighted by different authors [10,15], probably including also the ethnic sub-categories, as suggested by studies performed in the close populations $[13,15,20]$.

If possible, the scenario is even more fragmentary in case of children where a few articles are available concerning differences among skeletal classes: Utsuno et al., [19] in a Japanese population aged between 7 and 18 years concluded that skeletal class may explain the variability of facial measurements, as it depends upon the maxillary and mandibular positions which are affected by factors inhibiting or improving skeletal growth. Pithon et al., [20] analysed a NorthEastern Brazilian group of children aged between 8 and 12 years and found differences in thickness at stomion and pogonion (higher in Class III) and at the bottom lip, corresponding to labrale inferius (higher in Class II). However, no further anatomical considerations on these differences were provided.

In our previous study about midfacial soft-tissue thickness in children, we focused on the combined effects of sex and age, but we did not assess other biological characteristics of the patients [21]. The present study approached the problem from a different point of view, and verified the existence of a statistically significant difference between the three skeletal classes at labral superius and gnathion: overall, in both sexes Class II children had the thinnest soft tissues and Class III the thickest ones. Indeed, the results are difficult to discuss, as literature concerning the children is very limited; nevertheless, provide some food for thoughts. First, general rules concerning adults seem not to be entirely followed in case of children, as Class II shows lower thicknesses in labrale superius; from this point of view, the present data are concordant with several articles on adult population, where this specific difference has already been reported $[13,15,17]$.

In addition, the present investigation highlighted a statistically significant difference between Class II and III at gnathion which represents a novel information in comparison with existing literature.

Anyway, racial variability seems to be observed also in children, as the few available databases provide discordant results [20]. Therefore, the need for further studies including population data is clear, to improve the knowledge of ethnic differences concerning this anatomical detail.

For what concerns metrical measurements, no comparison can be performed with the few existing in literature because of differences in the experimental protocols: for example, Pithon et al., measured the distance at each facial landmark from the bone surface according to planes parallel to the Frankfurt plane [20], whereas the present study performed measurements following George's indications, following the same procedures applied in the previous article [21].

Another example of possible comparison derives from a previous article by Ferrario et al., [18]: in a group of orthodontic Class I and II patients aged 8 to 14 years, the authors analysed the thickness of facial soft tissues as a global value (area comprised between the soft tissue profile and the nasion-pogonion line) and found larger values in males and in Class II children [18]. They attributed the differences to size discrepancies, that disappeared after standardisation for facial height. Unfortunately, differences in both the method and the sample characteristics prevent a full comparison with the current investigation.

The dishomogeneous approaches to this topic, in children as in adults, prevent from acquiring comparable data, and explain difficulties in reaching a common interpretation of results. An important difference among articles is about skeletal class definition: usually sagittal differences between the maxillary and mandibular apical bases are assessed through ANB angle, but this parameter proved to be influenced by variations in maxillary position (assessed through SNA angle) and by rotation of the jaw (indicated by SN-GoMe angle [23],). In the current study, the skeletal class was assessed correcting ANB angle according to both maxillary position and mandibular rotation [18, 23]. 
For what concerns relationships with sex, the present study generally confirms results provided by the previous publication, as it confirms the generally higher facial soft tissue thickness in males than in females, especially in the middle and lower facial thirds [21].

Unfortunately, our sample size prevented us to divide the children also according to age, and this is a limitation of the investigation. In addition, other variables need to be taken adequately into consideration to gain a full knowledge of the relationship between soft tissues and skeletal class, such as the variability of teeth positions (overbite and overjet), dental formula and dynamics of growth, which still must be considered.

In conclusion, the present study provides a new contribution to the issue of links between facial surface and skeletal classes: further studies are needed to reach a standardization of assessment procedures and to verify the possible modifications due to ethnic factors.

\section{ETHICS APPROVAL AND CONSENT TO PARTICIPATE}

The article follows local and international ethic rules concerning retrospective studies. All the X-rays were anonymized.

\section{HUMAN AND ANIMAL RIGHTS}

All the reported experiments in accordance with the ethical standards of the committee responsible for human experimentation (institutional and national), and with the Helsinki Declaration of 1975, as revised in 2013 (http://ethics.iit.edu/ecodes/node/3931.

\section{CONSENT FOR PUBLICATION}

Written and informed consent was obtained for the study.

\section{CONFLICT OF INTEREST}

The authors confirm that this article content has no conflict of interest.

\section{ACKNOWLEGEMENTS}

Declared none.

\section{REFERENCES}

[1] Hamid S, Abuaffan AH. Facial soft tissue thickness in a sample of Sudanese adults with different occlusions. Forensic Sci Int 2016; 266: 209-14.

[http://dx.doi.org/10.1016/j.forsciint.2016.05.018] [PMID: 27314547]

[2] Arnett GW, Jelic JS, Kim J, et al. Soft tissue cephalometric analysis: Diagnosis and treatment planning of dentofacial deformity. Am J Orthod Dentofacial Orthop 1999; 116(3): 239-53.

[http://dx.doi.org/10.1016/S0889-5406(99)70234-9] [PMID: 10474095]

[3] Arnett GW, Gunson MJ. Facial planning for orthodontists and oral surgeons. Am J Orthod Dentofacial Orthop 2004; $126(3)$ : $290-5$. [http://dx.doi.org/10.1016/j.ajodo.2004.06.006] [PMID: 15356488]

[4] Cha KS. Soft-tissue thickness of South Korean adults with normal facial profiles. Korean J Orthod 2013; 43(4): 178-85. [http://dx.doi.org/10.4041/kjod.2013.43.4.178] [PMID: 24015387]

[5] Sforza C, Dolci C, Tommasi DG, Pisoni L, De Menezes M, Elamin F. Three-dimensional facial distances of Northern Sudanese persons from childhood to young adulthood. J Craniomaxillofac Surg 2014; 42(5): e318-26. [http://dx.doi.org/10.1016/j.jcms.2013.10.013] [PMID: 24290254]

[6] Sforza C, Dolci C, Dellavia C, Gibelli DM, Tartaglia GM, Elamin F. Abnormal variations in the facial soft tissues of individuals with Down syndrome: Sudan versus Italy. Cleft Palate Craniofac J 2015; 52(5): 588-96. [http://dx.doi.org/10.1597/14-082] [PMID: 25275539]

[7] Gibelli D, Codari M, Rosati R, et al. A quantitative analysis of lip aesthetics: The influence of gender and aging. Aesthetic Plast Surg 2015; 39(5): 771-6.

[http://dx.doi.org/10.1007/s00266-015-0495-7] [PMID: 25948067]

[8] Rosati R, Codari M, Maffessanti F, Dolci C, Ferrario VF, Sforza C. The labial aging process: A surface analysis-based three-dimensional evaluation. Aesthetic Plast Surg 2014; 38(1): 236-41. [http://dx.doi.org/10.1007/s00266-013-0227-9] [PMID: 24142116]

[9] Tartaglia GM, Dolci C, Sidequersky FV, Ferrario VF, Sforza C. Soft tissue facial morphometry before and after total oral rehabilitation with 
implant-supported prostheses. J Craniofac Surg 2012; 23(6): 1610-4.

[http://dx.doi.org/10.1097/SCS.0b013e31825af109] [PMID: 23147286]

[10] Wang J, Zhao X, Mi C, Raza I. The study on facial soft tissue thickness using Han population in Xinjiang. Forensic Sci Int 2016; 266: 585.e1-5.

[http://dx.doi.org/10.1016/j.forsciint.2016.04.032] [PMID: 27216250]

[11] Utsuno H, Kageyama T, Uchida K, Kibayashi K. Facial soft tissue thickness differences among three skeletal classes in Japanese population. Forensic Sci Int 2014; 236: 175-80.

[http://dx.doi.org/10.1016/j.forsciint.2013.12.040] [PMID: 24509238]

[12] Utsuno H, Kageyama T, Uchida K, et al. Pilot study of facial soft tissue thickness differences among three skeletal classes in Japanese females. Forensic Sci Int 2010; 195(1-3): 165.e1-5.

[http://dx.doi.org/10.1016/j.forsciint.2009.10.013] [PMID: 19942386]

[13] Kurkcuoglu A, Pelin C, Ozener B, Zagyapan R, Sahinoglu Z, Yazici AC. Facial soft tissue thickness in individuals with different occlusion patterns in adult Turkish subjects. Homo 2011; 62(4): 288-97. [http://dx.doi.org/10.1016/j.jchb.2011.06.001] [PMID: 21741647]

[14] Lee YJ, Park JT, Cha JY. Perioral soft tissue evaluation of skeletal Class II Division 1: A lateral cephalometric study. Am J Orthod Dentofacial Orthop 2015; 148(3): 405-13.

[http://dx.doi.org/10.1016/j.ajodo.2015.03.033] [PMID: 26321338]

[15] Kamak H, Celikoglu M. Facial soft tissue thickness among skeletal malocclusions: Is there a difference? Korean J Orthod 2012 ; 42 (1): 23-31. [http://dx.doi.org/10.4041/kjod.2012.42.1.23] [PMID: 23112928]

[16] Hoffelder LB, de Lima EM, Martinelli FL, Bolognese AM. Soft-tissue changes during facial growth in skeletal Class II individuals. Am J Orthod Dentofacial Orthop 2007; 131(4): 490-5.

[http://dx.doi.org/10.1016/j.ajodo.2005.12.030] [PMID: 17418715]

[17] Gungor K, Bulut O, Hizliol I, Hekimoglu B, Gurcan S. Variations of midline facial soft tissue thicknesses among three skeletal classes in Central Anatolian adults. Leg Med (Tokyo) 2015; 17(6): 459-66. [http://dx.doi.org/10.1016/j.legalmed.2015.09.001] [PMID: 26593990]

[18] Ferrario VF, Sforza C. Size and shape of soft-tissue facial profile: Effects of age, gender, and skeletal class. Cleft Palate Craniofac J 1997; 34(6): 498-504.

[http://dx.doi.org/10.1597/1545-1569(1997)034<0498:SASOST>2.3.CO;2] [PMID: 9431467]

[19] Utsuno H, Kageyama T, Uchida K, Yoshino M, Miyazawa H, Inoue K. Facial soft tissue thickness in Japanese children. Forensic Sci Int 2010; 199(1-3): 109.e1-6.

[http://dx.doi.org/10.1016/j.forsciint.2010.02.016] [PMID: 20347239]

[20] Pithon MM, Rodrigues Ribeiro DL, Lacerda dos Santos R, Leite de Santana C, Pedrosa Cruz JP. Soft tissue thickness in young north eastern Brazilian individuals with different skeletal classes. J Forensic Leg Med 2014; 22: 115-20. [http://dx.doi.org/10.1016/j.jflm.2013.09.014] [PMID: 24485435]

[21] Gibelli D, Collini F, Porta D, et al. Variations of midfacial soft-tissue thickness in subjects aged between 6 and $18 y e a r s$ for the reconstruction of the profile: A study on an Italian sample. Leg Med (Tokyo) 2016; 22: 68-74. [http://dx.doi.org/10.1016/j.legalmed.2016.08.005] [PMID: 27591543]

[22] George RM. The lateral craniographic method of facial reconstruction. J Forensic Sci 1987; 32: 239-43. [http://dx.doi.org/10.1520/JFS11181J]

[23] Miralles R, Hevia R, Contreras L, Carvajal R, Bull R, Manns A. Patterns of electromyographic activity in subjects with different skeletal facial types. Angle Orthod 1991; 61(4): 277-84. [PMID: 1763838]

[24] Dumont ER. Mid-facial tissue depths of white children: An aid in facial feature reconstruction. J Forensic Sci 1986; $31(4)$ : $1463-9$. [http://dx.doi.org/10.1520/JFS11926J] [PMID: 3783111]

(C) 2018 Gibelli et al.

This is an open access article distributed under the terms of the Creative Commons Attribution 4.0 International Public License (CC-BY 4.0), a copy of which is available at: (https://creativecommons.org/licenses/by/4.0/legalcode). This license permits unrestricted use, distribution, and reproduction in any medium, provided the original author and source are credited. 